American Journal of Pharmaceutical Education 2017; 81 (3) Article 51.

\title{
RESEARCH
}

\section{An Analysis of Quality Improvement Education at US Colleges of Pharmacy}

Janet Cooley, PharmD, ${ }^{a}$ Samuel F. Stolpe, PharmD, ${ }^{\mathrm{b}}$ Amber Montoya, PharmD, ${ }^{\mathrm{a}}$ Angela Walsh, PharmD, ${ }^{\mathrm{c}}$ Ana L. Hincapie, PhD, ${ }^{\mathrm{d}}$ Vibhuti Arya, PharmD, ${ }^{\mathrm{e}}$ Melissa L. Nelson, ${ }^{\mathrm{a}}$ Terri Warholak, PhD ${ }^{\mathrm{a}}$

${ }^{a}$ University of Arizona College of Pharmacy, Tucson, Arizona

${ }^{\mathrm{b}}$ Pharmacy Quality Alliance, West Springfield, Virginia

${ }^{c}$ Tucson Medical Center, Tucson, Arizona

d James L. Winkle College of Pharmacy, University of Cincinnati, Cincinnati, Ohio

e St. John's University College of Pharmacy and Health Sciences, New York City, New York

Submitted November 11, 2015; accepted April 6, 2016; published April 2017.

Objective. Analyze quality improvement (QI) education across US pharmacy programs.

Methods. This was a two stage cross-sectional study that inspected each accredited school website for published QI curriculum or related content, and e-mailed a questionnaire to each school asking about QI curriculum or content. T-test and chi square were used for analysis with an alpha a priori set at .05. Results. Sixty responses (47\% response rate) revealed the least-covered QI topics: quality dashboards / sentinel systems (30\%); six-sigma or other QI methodologies $(45 \%)$; safety and quality measures (57\%); Medicare Star measures and payment incentives (58\%); and how to implement changes to improve quality (60\%). More private institutions covered Adverse Drug Events than public institutions and required a dedicated QI class; however, required QI projects were more often reported by public institutions.

Conclusion. Despite the need for pharmacists to understand QI, it is not covered well in school curricula.

Keywords: quality improvement, quality measurement, quality control, safety, medication error reduction

\section{INTRODUCTION}

Quality improvement (QI), as defined by the Health Resources and Services Administration (HRSA), "consists of systematic and continuous actions that lead to measurable improvement in health care services and the health status of targeted patient groups." "The Institute of Medicine has indicated that each health care team member should be well versed in QI so that the quality and safety of care can be continuously improved. ${ }^{2}$

Advancing quality improvement concepts in pharmacy education has been a focus of the Accreditation Council for Pharmacy Education (ACPE) in recent years for all doctor of pharmacy (PharmD) programs across the United States (US). ${ }^{3}$ The American Association of Colleges of Pharmacy (AACP) and The Center for the Advancement of Pharmaceutical Education (CAPE) also

Corresponding Author: Janet Cooley, University of Arizona College of Pharmacy, 1295 N Martin Ave., PO Box 210202, Tucson, AZ 85721-0202. Tel: 520-626-5095. Fax: 520-6264063. E-mail: cooley@pharmacy.arizona.edu

(Note: At the time of this study, Drs. Montoya and Walsh were PharmD candidates at the University of Arizona College of Pharmacy.) formally endorse QI as one of their educational outcomes. $^{4}$

The extent of QI education may vary among the PharmD programs, but there is no denying its importance and impact on a pharmacist's career. Pharmacists and other health care professionals can expect increasing levels of accountability for performance on health care quality metrics in today's health care environment. ${ }^{5}$ In fact, the ACPE standards state that "application of ... quality metrics to advance patient care and service delivery within and between various practice settings" should be included as part of the required elements for didactic education in PharmD programs. ${ }^{4}$ Encouraging education in quality improvement begins with demonstrating its significance and relevance within a pharmacy student's education and career.

The increased relevance of health care quality in the marketplace and pharmacy practice can be used to demonstrate its applicability and importance to pharmacy students. A 2004 study by Jackson shared self-reported data demonstrating that the application of QI concepts in PharmD programs improved students' ability to identify errors, implement methods to decrease errors in their 


\section{American Journal of Pharmaceutical Education 2017; 81 (3) Article 51.}

practice setting, and raise awareness of the impact these errors can have on the health of a patient. ${ }^{6}$ A study by Gilligan and colleagues assessed both instructors' and students' perceptions of implementing QI education in the curriculum. ${ }^{7}$ In this study, five colleges of pharmacy that utilized some portion of the EPIQ ("Educating Pharmacy Students and Pharmacists to Improve Quality" now called "Educating Pharmacists in Quality"; Alexandria, Virginia) educational program demonstrated a statistically significant improvement in students' self-reported QI knowledge. The EPIQ program is a possible model that other colleges of pharmacy may adopt to improve both student QI knowledge and attitudes. ${ }^{7-10}$ The EPIQ training program and additional resources are available through the Pharmacy Quality Alliance (PQA) website. ${ }^{11}$ The PQA has developed multiple measures of safe and appropriate medication use that are currently utilized by federal and state quality programs. PQA “... collaboratively promotes appropriate medication use and develops strategies for measuring and reporting performance information related to medications." 12 Measures developed and implemented by PQA are specifically designed to be sensitive to pharmacist intervention. PQA medication safety and management measures include metrics such as statin use in patients with diabetes, high risk medications in the elderly, comprehensive medication review completion rate, and adherence measures for statins, diabetes medications, and antihypertensives. The EPIQ modules refer to these measures and facilitate discussion about the importance of QI education so students and pharmacists are better prepared to discuss implications of these metrics in pharmacy practice.

While several studies have examined the application of specific QI concepts within pharmacy curricula, a review of the literature found that recently published studies did not delve into the extent and frequency to which QI concepts were covered nor offer a comparison between the PharmD programs in the US. ${ }^{7-10}$ More than a decade ago, however, a descriptive study conducted by Johnson and Latif investigated the quality and quantity of medication error reduction, a component of QI education, in pharmacy curricula. ${ }^{13}$ The investigators found that the depth and frequency of medication error instruction within pharmacy curricula was highly variable, lacked standardization, and did not include key medication error instruction components. However with a great emphasis currently placed on QI education by the ACPE and CAPE Educational Outcomes and a shift in focus within pharmacy practice to quality and patient outcomes, it has become apparent that a measure of the current status of PharmD QI education is needed. ${ }^{3,4}$ The main purpose of this study, therefore, was to explore the breadth and depth of QI education currently offered across accredited PharmD programs in the US. A secondary objective of this study was to propose a tentative QI curriculum that could be used as guideline for pharmacy programs.

\section{METHODS}

This cross-sectional study used data obtained from a website search (phase 1) and questionnaires (phase 2) that were completed using electronic, mail, or telephone interviews. This study was approved by the University of Arizona Human Subjects Protection Program (UA IRB).

Phase one consisted of data collection through an online website search for each college of pharmacy to determine if QI concepts were implemented into the college's curriculum. If available, contact information for a QI instructor was identified so that person could be sent the questionnaire in phase two. To standardize the website search, a data collection form was developed (available upon request) and data were collected by multiple researchers. Another researcher triangulated the data collected and confirmed all data were collected in the same manner by performing a quality check on $10 \%$ of the data entries.

Phase two included a cross-sectional questionnaire. Questions were adapted from two previously described cross-sectional questionnaires that also measured curriculum inclusion of content across ACPE accredited colleges/schools of pharmacy. ${ }^{14,15}$ The questionnaire originally included 46 questions and respondents had four options for completing the questionnaire: electronic, paper, making an appointment with a researcher for completion via phone, or in-person at the PQA annual meeting in May 2014, or at the AACP Annual Meeting in July 2014. If the respondent indicated that his/her college/ school had QI content, syllabus copies were requested. Depending on the method of response, a follow-up phone call to discuss or complete the questionnaire was performed upon respondent request. Care was taken to confirm that each school was accounted for only once in data collection.

The questionnaire was emailed up to three times to non-responders. Each wave was separated by approximately two weeks. In order to decrease response burden, the questionnaire was subsequently reduced to 13 questions and offered electronically through Survey Monkey. The questions that were kept in the survey are reported in this article. The questions that were eliminated from the longer version of the survey included specific information about methods of learning applied in QI programs, number of credit hours dedicated to QI, questions about 


\section{American Journal of Pharmaceutical Education 2017; 81 (3) Article 51.}

grading QI, and detailed questions specifically about QI project logistics. Respondents who had not yielded a response after the third wave received the shortened questionnaire. In addition, an incentive of enrolling in a raffle for a \$25 gift card was offered upon completion of the survey for all respondents. The abbreviated version of the questionnaire was sent only once. The UA IRB approved this protocol revision.

Additionally, literature ${ }^{16}$ that recognized colleges or schools of pharmacy requiring a senior research project was cross-referenced with this study to identify those programs that may require both senior research projects and/ or QI projects.

To be eligible for this study, each participant must have been a faculty member at a US school or college of pharmacy that was ACPE-accredited ("regular") as of January $2014 .{ }^{17}$ One person, preferably someone who taught or conducted research in QI, was targeted to answer the questionnaire at each college or school. That person was identified for each program via the following methods: 1) each ACPE-accredited pharmacy college or school website was searched to reveal the presence of published online QI curriculum or other related content and to identify QI instructor's contact information if available; 2) faculty web pages were examined to identify faculty who had an interest in or who were doing research in QI; 3) a literature search was performed to identify pharmacy faculty who were publishing in the realm of QI, using the following keywords: quality control; safety; medication error reduction; quality improvement; medication errors; research project; and pharmacy curriculum; 4) Pharmacy Quality Alliance (PQA) Education Committee pharmacy faculty members were contacted; and/or 5) faculty who requested a copy of the EPIQ program from PQA were identified. In the case that multiple persons from the same college or school were identified as teaching QI, individuals were contacted to determine who had the primary QI teaching responsibility.

The primary dependent variable was the presence or absence of QI education and the extent of which the subject was covered at each college or school of pharmacy. Demographic variables included: type of pharmacy college or school (public or private); length of the doctor of pharmacy program $(3,4,0-6$ years); class size; the college's definition of QI (definition and keywords used by each program); QI course type (required or elective, integrated or standalone, interprofessional); extent of instruction (full course, a few hours, single lecture; total number of hours); who taught the QI course (if applicable, obtain course syllabus); QI project (optional or required, individual or group, presentation required, poster required, overall extent, research topics); number of credit hours; classroom versus experiential time for QI material; extent of experiential time (site visits) with QI focus; extent of classroom work/type of learning (case-based, team-based, lecture, combination, other) for QI material; innovative components; and any other demographics the college or school provided.

Continuous data were summarized using means and standard deviations; independent groups were compared using a $t$-test. Categorical variables were summarized as percentages and frequency counts. Chi-square analysis was used to compare nominal data. The a priori alpha level was set to .05 .

\section{RESULTS}

Sixty responses were returned from the 129 accredited schools ( $47 \%$ response rate). The 60 respondents were deemed to be representative of pharmacy schools overall with no significant difference between the general make-up of the study respondents and US accredited colleges or schools of pharmacy (and precandidate status). ${ }^{18,19}$ Respondent characteristics are displayed in Table 1. In this study, $46.7 \%$ of respondents indicated that their college or school is public $(50 \%$ of the US accredited and pre-candidate schools are public) and $48.3 \%$ of respondents indicated that their college or school is private (currently $52.2 \%$ of the US accredited and pre-candidate schools are private).

Respondents indicated that the least covered QI topics in their curricula (Table 2) were: quality dashboards and sentinel systems (30\%); six-sigma, or other QI methodologies (45\%); state quality improvement laws $(50 \%)$; measures of safety and quality (56.7\%); Medicare Star measures (a national performance measurement program) and payment incentives (58.3\%); and how to implement changes to improve quality $(60 \%)$. The most commonly covered QI topics were (Table 2): medication errors: prevention and reporting $(81.7 \%)$; organizations involved in quality ( $80 \%$ ); quality and the future of health care: health care reform, Patient Protection and Affordable Care Act (78.3\%); medication reconciliation (76.7\%); drug-drug interactions (75\%); and adverse drug events $(75 \%)$.

More private schools covered adverse drug events than public schools $(p=.039$, Table 2$)$. There were no significant differences in regard to pharmacy college or school program length (3-year versus 4-year) among the QI topics listed on the questionnaire (Table 2).

Requiring a QI class (in any type of format; required standalone, elective standalone, part of another class or as independent study) was more likely to be reported in private schools ( $p=.003$; Table 3 ) while requiring a QI project was more often reported by public schools $(p=.014$, 
American Journal of Pharmaceutical Education 2017; 81 (3) Article 51.

Table 1. Characteristics of Study Participants

\begin{tabular}{|c|c|c|}
\hline & Study Participants & $\begin{array}{c}\text { Colleges and schools of pharmacy with } \\
\text { ACPE }^{1} \text { accreditation or pre-candidate status as of } \\
\text { July } 2015 \\
\end{array}$ \\
\hline Characteristic & $\mathrm{N}(\%)$ Total $\mathrm{N}=60$ & N (\%) Total N=132 \\
\hline \multicolumn{3}{|l|}{ College System $(\mathrm{N}=57)$} \\
\hline Semester & $51(85)$ & \\
\hline Quarter & $6(10)$ & NA \\
\hline \multicolumn{3}{|l|}{ Academic Schedule $(\mathrm{N}=45)$} \\
\hline Year-Round & $7(11.7)$ & \\
\hline Standard & $38(63.3)$ & NA \\
\hline \multicolumn{3}{|l|}{ Prerequisites Required $(\mathrm{N}=43)$} \\
\hline 2 years & $29(48.3)$ & NA \\
\hline 3 years & $10(16.7)$ & NA \\
\hline 4 years/Bachelor's degree & $3(5.0)$ & $9(6.8)$ \\
\hline Other & $1(1.7)$ & NA \\
\hline \multicolumn{3}{|l|}{ Institution Type $(\mathrm{N}=57)^{2}$} \\
\hline Public & $28(46.7)$ & $66(50.0)$ \\
\hline Private & $29(48.3)$ & $69(52.2)$ \\
\hline Other & $0(0)$ & $0(0)$ \\
\hline \multicolumn{3}{|l|}{ Program Length $(\mathrm{N}=56)^{3}$} \\
\hline 3 years & $4(6.7)$ & $12(9.1)$ \\
\hline 4 years & $51(85)$ & $116(87.8)$ \\
\hline Other & $1(1.7)$ & $7(5.3)$ \\
\hline \multicolumn{3}{|c|}{ Interprofessional presence $(\mathrm{N}=43)$} \\
\hline Yes & $15(25)$ & \\
\hline No & $28(46.7)$ & NA \\
\hline \multicolumn{3}{|c|}{$\begin{array}{l}\text { Pharmacy Quality Alliance (PQA) } \\
\text { member }(\mathrm{N}=22)\end{array}$} \\
\hline Yes & $11(18.3)$ & \\
\hline No & $5(8.3)$ & \\
\hline Don't know & $6(10.0)$ & NA \\
\hline Class Size & Mean (SD), Range, N & Mean (SD), Range, N \\
\hline Class of 2014 & $128(63.0), 0-320,55$ & $123(57.0), 36-330,130$ \\
\hline Class of 2017 & $129(58.7), 40-300,57$ & NA \\
\hline
\end{tabular}

${ }^{1}$ ACPE: Accreditation Council for Pharmacy Education

${ }^{2}$ Chi-Square tests revealed a $p$ value of .97

${ }^{3}$ Chi-Square tests revealed a $p$ value of .5

Table 3). There were no significant differences for the college or school of pharmacy program lengths.

Of the 60 returned responses, 16 pharmacy schools required a QI class and seven pharmacy schools required a QI project. Of the aforementioned schools, there were five pharmacy schools that overlapped and required both a QI class and a QI project. Previous data that located colleges or schools of pharmacy requiring a senior research project was cross-referenced with this study; of the 12 colleges or schools of pharmacy requiring a senior research project, two require senior research projects, QI classes, and QI projects. ${ }^{16}$

\section{DISCUSSION}

Health care is rapidly shifting from a fee-for-service system to one that emphasizes value through various pay-for-performance models; thus, the importance of offering high quality of care to patients in an affordable way has never been greater, and pharmacists are an integral part of this shift. ${ }^{5}$ A shift in accountability necessitates that pharmacists are prepared to take on that accountability. Yet, as the results from this study demonstrate, QI education in schools of pharmacy has not yet become a priority.

The federal government is leading the effort in quality improvement standards in several settings. The Centers for Medicare and Medicaid Services (CMS) has launched quality improvement programs for physicians, nursing homes, hospice programs, and even Medicare Part D Prescription Drug plans, which provide senior beneficiaries coverage of their medicines. ${ }^{20}$ The CMS 
American Journal of Pharmaceutical Education 2017; 81 (3) Article 51.

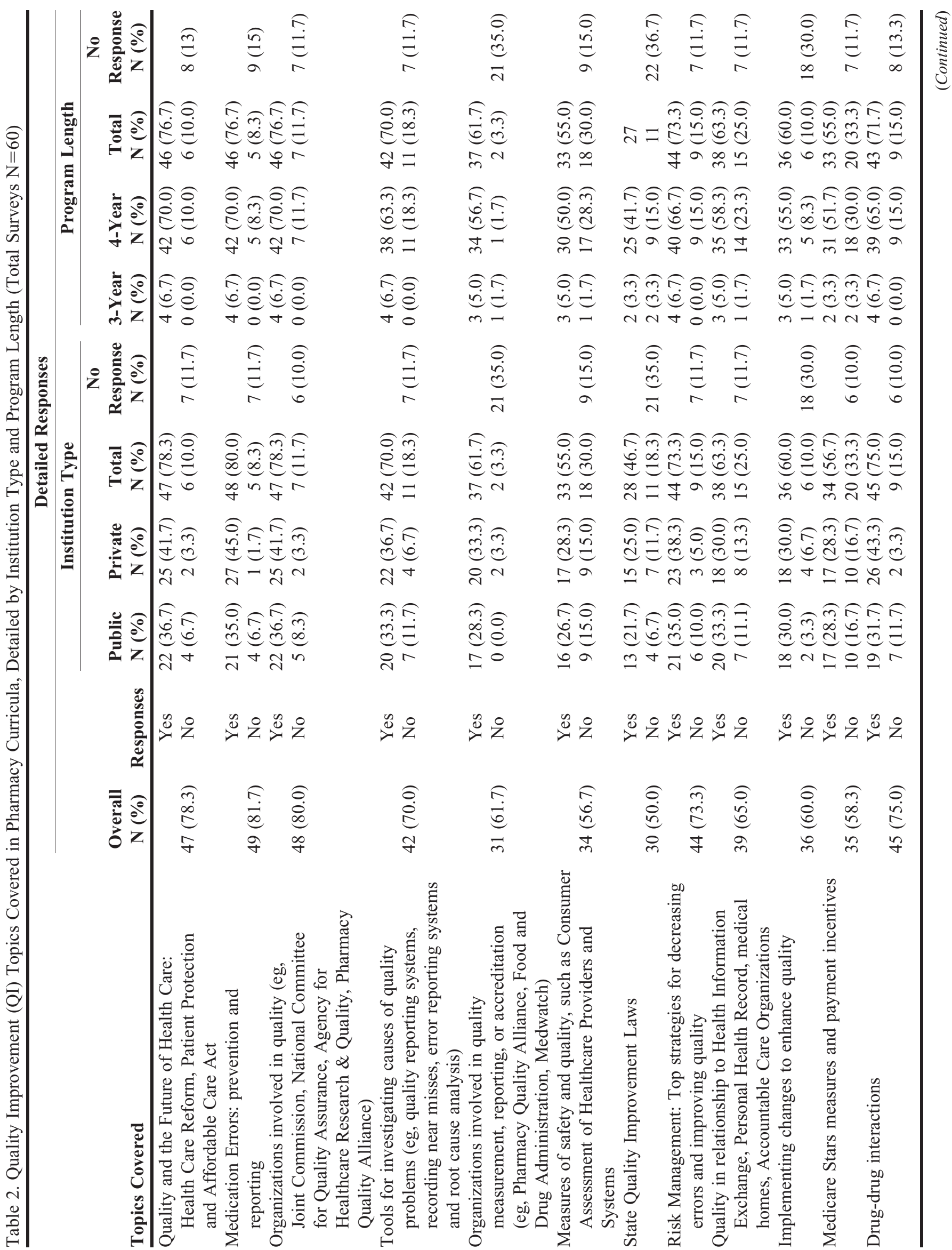


American Journal of Pharmaceutical Education 2017; 81 (3) Article 51.

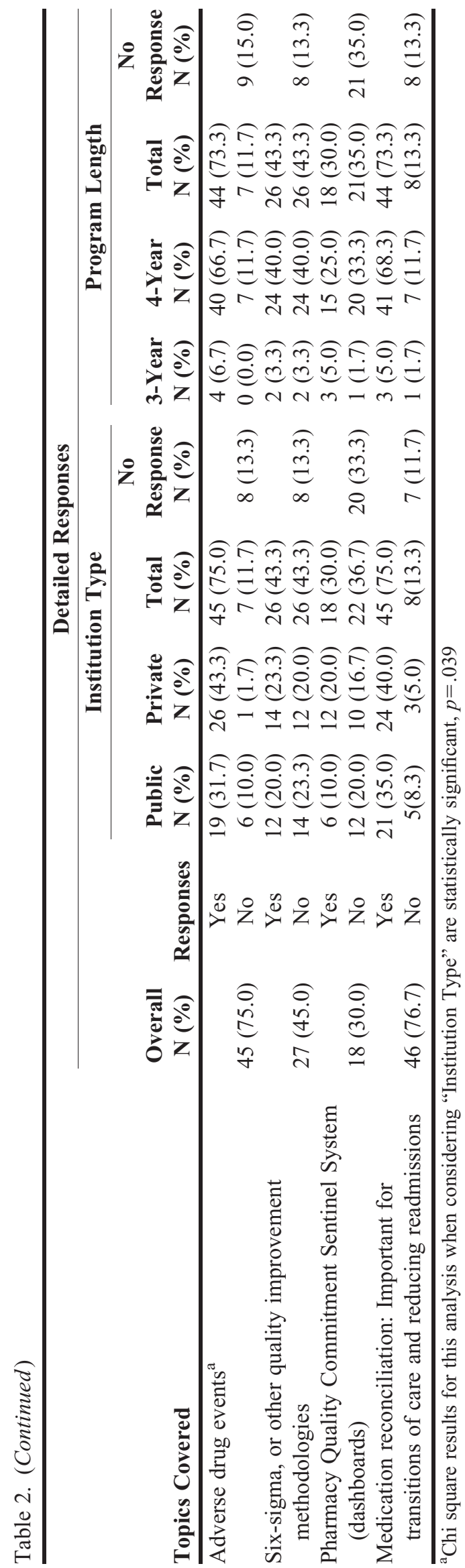

Star Rating System assesses medication safety and appropriateness, among other things, and pharmacists drive improvement in these performance metrics and the ultimate optimization of patient care. In fact, payers are beginning to identify pharmacist intervention as a fundamental way in which to improve safety for beneficiaries and increase medication adherence, which has led to several pay for performance models in the marketplace. ${ }^{21}$ Yet, only $58 \%$ of our respondents reported teaching the Medicare Star measures and payment incentives. This represents just one example of the many QI topics that can help PharmD students succeed in the changing health care system and grow with the profession of pharmacy. The need for quality and safety training is not limited to pharmacy education. Similar results have been found in studies assessing quality and safety education in US and Canadian medical schools. ${ }^{22,23}$

The primary findings of this study indicate that in pharmacy schools, the broadest topics are taught the least often, and more pharmacy-specific topics are covered more frequently in pharmacy QI courses. For example, six-sigma, pharmacy quality dashboards, and Medicare STAR ratings are discussed least often, while adverse event reporting, medication reconciliation, and drug-drug interactions are addressed most often. This may be because there has been a focus on adding adverse event reporting, medication reconciliation, and drug-drug interactions into education for some time whereas the other topics are "newer" and more reflective of recent changes in the US health care system. ${ }^{13}$ It may take colleges or schools of pharmacy time to adapt and to add these topics to the PharmD curricula. Additionally, the pharmacy specific topics may be seen as fitting into the traditional model of pharmacy practice, whereas the broader topics may be seen as "outside" of the traditional role of the pharmacist. Nonetheless, with the changing landscape of the US health care system, the broader and least covered topics of six-sigma, pharmacy quality dashboards and Medicare STAR ratings are becoming more of a necessity to demonstrate the value of pharmacist services in the larger context of the health care market.

Another concern is that there are some programs that do not teach students the concept of how to improve quality. Pharmacists must know at a most basic level how to improve quality, whether it is on a small scale (improving workplace and workflow quality) or on a large scale (improving outcomes and patient satisfaction).,2,3

Interestingly, requiring a QI class was more likely in private schools, while requiring a QI project was more often reported by public schools. These differences 


\section{American Journal of Pharmaceutical Education 2017; 81 (3) Article 51.}

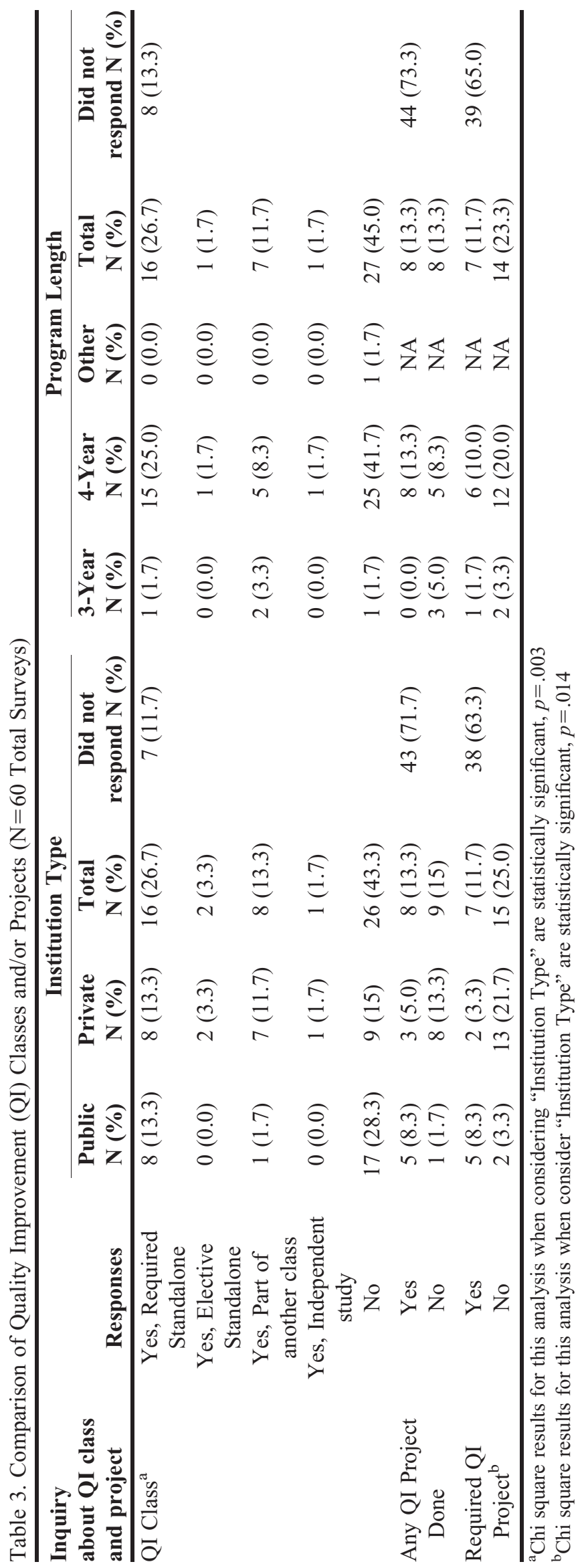

in curricula are difficult to explain and require further research. Studies have previously shown that students gain a greater understanding and appreciation of quality improvement principles when completing a project. ${ }^{6-8,23}$ Gilligan and colleagues reported more change in knowledge and attitudes when the program included a QI project as part of the educational experience. ${ }^{7}$ Additionally both preceptor and faculty selfreported attitudes are improved with the use of the EPIQ program. ${ }^{9,10}$

From the returned responses, about $27 \%$ of colleges or schools of pharmacy require a standalone class dedicated to QI. These results are similar to those reported by Smith and colleagues who found standalone QI classes in only $20 \%$ of nursing schools. ${ }^{24}$ QI projects, which are required in about $12 \%$ of our study respondents' institutions, may offer more opportunities for learning, professional development, and academic distinction. Furthermore, there are two reported colleges or schools of pharmacy nationwide $(3 \%$ of respondents) that require a QI class, QI project, and a senior research project. Further research will shed light on the outcomes for students who participate in programs with this extensive emphasis on QI and research.

Future research will consist of further data collection to more completely describe the QI curricula being offered within ACPE accredited colleges or schools of pharmacy. To date, an all-encompassing nationwide survey of QI education/curricula has not yet been performed. However, with a $47 \%$ response rate, more data is needed to determine if any other differences exist. Additional research will be conducted to describe exemplary colleges or schools of pharmacy that have implemented QI curricula, and will focus on describing specific programs and their QI curricula more in-depth. The goal will be to highlight examples of best practices, such as an elective QI class, required class, interprofessional class, integrated class, and project.

The profession of pharmacy is constantly changing. In order for graduates to be practicing at the highest level, they must be ready to participate in a health care system that is driven by quality and outcomes. Schools and colleges of pharmacy can use the list of topics generated for this survey to start a conversation within their curriculum committees to decide how to best incorporate these important topics. Additionally, the EPIQ training program offered by PQA is a possible model that other colleges or schools of pharmacy may adopt to improve both QI knowledge and knowledge attitudes. ${ }^{7-11}$ Table 4 depicts a proposed QI curriculum based on EPIQ training program offered by PQA. ${ }^{11,12}$ 


\section{American Journal of Pharmaceutical Education 2017; 81 (3) Article 51.}

Table 4. Proposed Quality Improvement (QI) Curriculum Guideline

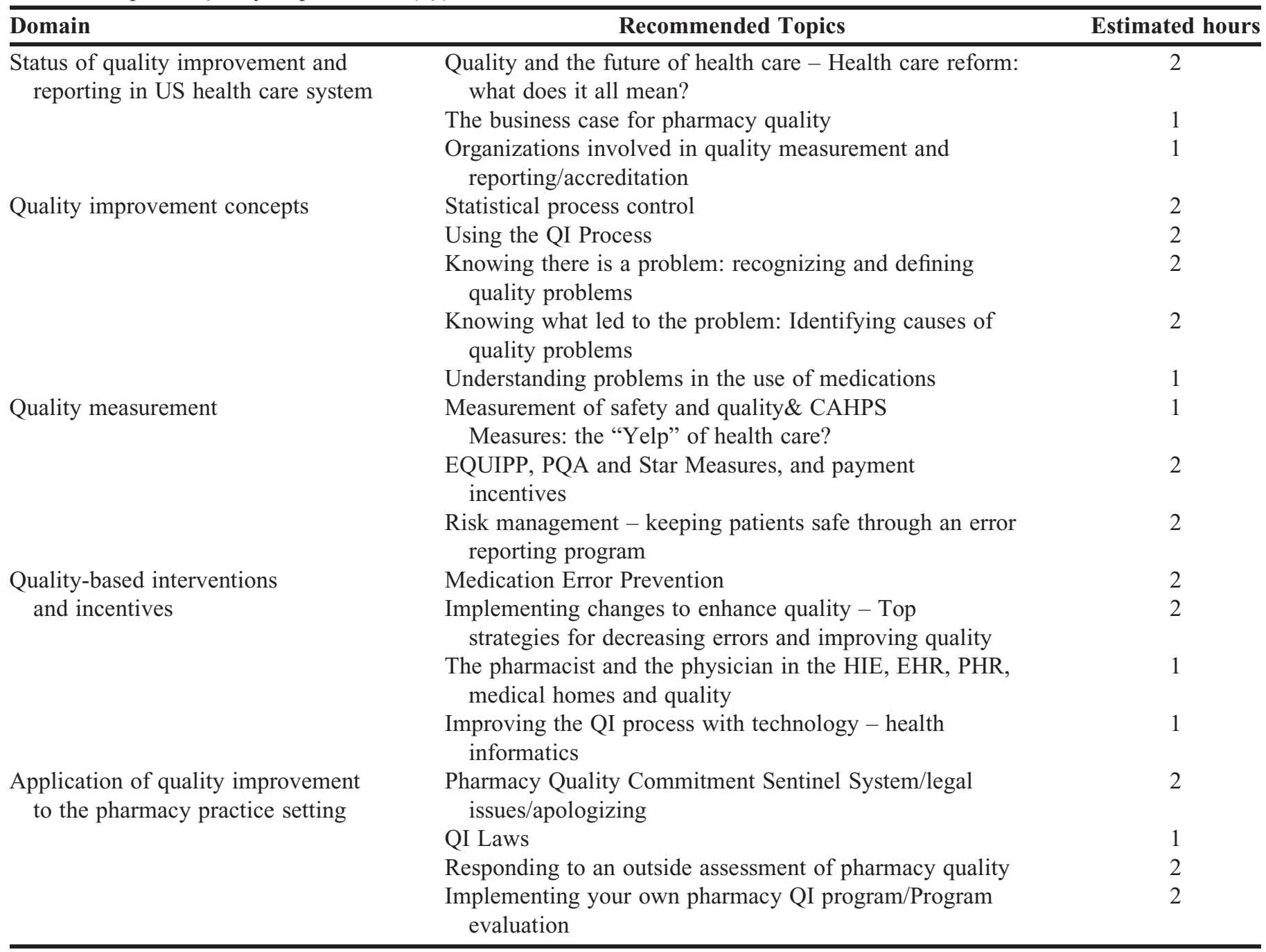

This study assumed that the respondents were familiar with the respective college or school of pharmacy's QI curriculum and were able to respond appropriately. This study was limited by the small sample size and the lower than anticipated response rate. Additionally, it was sometimes difficult to locate the individual at each college or school of pharmacy who was most familiar with that program's QI curricula. In some cases, the QI specialist was no longer at that institution and another faculty member had to fill out the questionnaire to their best ability, which was sometimes not comprehensive and could be incorrect or incomplete.

\section{CONCLUSION}

To the investigators' knowledge, this is the first national study to map the state of QI education in US pharmacy schools. The results of this study will help inform pharmacy and other health-related professional programs in the integration of QI concepts into their curriculum.

\section{ACKNOWLEDGMENTS}

The authors thank their student researchers, Bethsy M. Jacob, Hyun Jung Kim and Gabriel Navoa for their assistance and dedication in data collection. Without their contribution, this research would not have been possible.

\section{REFERENCES}

1. U.S. Department of Health and Human Services. Quality improvement. Health Resources and Services Administration. http:// www.hrsa.gov/quality/toolbox/methodology/qualityimprovement/. Accessed March 25, 2016.

2. Institute of Medicine. Crossing the Quality Chasm: A New Health System for the 21st Century. Washington, DC: National Academy Press; 2001.

3. Accreditation Council for Pharmacy Education. Accreditation standards and key elements for the professional program in pharmacy 


\section{American Journal of Pharmaceutical Education 2017; 81 (3) Article 51.}

leading to the doctor of pharmacy degree. Standards 2016. https:// www.acpe-accredit.org/pdf/Standards2016FINAL.pdf.

4. Medina MS, Plaza CM, Stowe CD, et al. Center for the Advancement of Pharmacy Education (CAPE) Educational Outcomes 2013. Am J Pharm Educ. 2013;77(8):Article 162. 5. Burwell SM. Setting value-based payment goals - HHS efforts to improve U.S. health care. N Engl J Med. 2015;372(10):897-899.

6. Jackson TL. Application of quality assurance principles: teaching medication error reduction skills in a "real world" environment. $A m J$ Pharm Educ. 2004;68(1):Article 17.

7. Gilligan AM, Myers J, Nash JD, et al. Educating pharmacy students to improve quality (EPIQ) in colleges and schools of pharmacy. Am J Pharm Educ. 2012;76(6)Article 109.

8. Warholak TL, West D, Holdford DA. The educating pharmacy students and pharmacists to improve quality program: tool for pharmacy practice. J Am Pharm Assoc. 2010;50(4):534538 .

9. Warholak TL, Noureldin M, West D, Holdford D. Faculty perceptions of the educating pharmacy students to improve quality (EPIQ) program. Am J Pharm Educ. 2011;75(8):Article 163. 10. Warholak TL. Preceptor perceptions of pharmacy student team quality assurance projects. Am J Pharm Educ. 2009;73(3):Article 47. 11. Warholak TL, Arya V, Hincapie A, Holdford D, West-Strum D. Educating Pharmacists in Quality (EPIQ). Pharmacy Quality Alliance. 2015. http://pqaalliance.org/academic/epiq/welcome.asp. Accessed March 25, 2016.

12. PQA Performance Measures. 2015. Pharmacy Quality Alliance. http://pqaalliance.org/measures/default.asp. Accessed March 25, 2016.

13. Johnson MS, Latif DA, Gordon B. Medication error instruction in schools of pharmacy curricula: a descriptive study. Am J Pharm Educ. 2002;66(4):364-371.

14. Murphy JE, Slack MK, Boesen KP, Kirking DM. Researchrelated coursework and research experiences in doctor of pharmacy programs. Am J Pharm Educ. 2007;71(6):Article 113.
15. Weddle P, Phan HP, Warholak T. Pediatric education diagnosis survey (PEDS): analyzing pediatric education within PharmD programs in the United States. [Senior project]. University of Arizona College of Pharmacy, 2013.

16. Sherbeck V, Murphy JE. Research-related coursework and research experiences in doctor of pharmacy programs. [senior project]. University of Arizona College of Pharmacy, 2014.

17. AACP institutional members, 2014. American Association of Colleges of Pharmacy. http://www.aacp.org/about/membership/ institutionalmembership/Pages/usinstitutionalmember.aspx. Accessed April 20, 2017.

18. Academic pharmacy's vital statistics. American Association of Colleges of Pharmacy. http://www.aacp.org/about/pages/vitalstats. aspx. Accessed March 25, 2016.

19. Pharmacy school admission requirements. American Association of Colleges of Pharmacy. http://www.aacp.org/resources/student/ pharmacyforyou/admissions/admissionrequirements/Documents/ Table\%205.pdf. Accessed March 25, 2016.

20. PQRS Training Module: Quality Measurement 101. eHealth University. Centers for Medicare and Medicaid Services (CMS). August 2014. http://www.cms.gov/eHealth/downloads/eHealthU_ PQRSQualityManagement101.pdf. Accessed March 25, 2016. 21. Pay For Performance (P4P) Program. Inland Empire Health Plan. https://ww3.iehp.org/en/providers/pharmaceutical-services/ pharmacy-p4p-program. Accessed March 25, 2016.

22. Alper E, Rosenberg EI, O’Brien KE, Fischer M, Durning SJ. Patient safety education at U.S. and Canadian medical schools: results from the 2006 Clerkship Directors in Internal Medicine survey. Acad Med. 2009;84(12):1672-1676.

23. Wong BM, Etchells EE, Kuper A, Levinson W, Shojania KG. Teaching quality improvement and patient safety to trainees: a systematic review. Acad Med. 2010;85(9):1425-1439.

24. Smith EL, Cronenwett L, Sherwood G. Current assessments of quality and safety education in nursing. Nurs Outlook. 2007;55(3): 132-137. 